\title{
Validation and upgrading of the recommended cross section data of charged particle monitor reactions
}

\author{
S. Takács ${ }^{1, a}$, F. Tárkányi ${ }^{1}$, and A. Hermanne ${ }^{2}$ \\ 1 Institute of Nuclear Research of the Hungarian Academy of Sciences, Debrecen 4026, Hungary \\ 2 Vrije Universiteit Brussel, Cyclotron Laboratory, 1090 Brussels, Belgium
}

\begin{abstract}
An upgrade and validation test of the recommended cross section database for charged particle reactions used for monitoring incident particle beams, published by the IAEA in 2001, is presented. In this upgrading process experimental cross sections published earlier, and not yet included in the evaluation work, or data measured recently were collected and added to the initial database in order to improve the quality of the recommended data. In the study 8 proton, 5 deuteron, 3 helium-3 and 6 alpha particle induced monitor reactions on $\mathrm{Al}, \mathrm{Ti}, \mathrm{Fe}, \mathrm{Ni}$ and $\mathrm{Cu}$ targets were included. In general the newly compiled experimental results support the previous recommended data, but in a few cases they influence the decision and result in a slightly different group of selected cross section data sets and hence in new recommended cross section values. Spline fitting method was used to calculate the new recommended data from the selected data sets. For benchmarking and validation of the recommended cross section data, experimental thick target yields were collected from literature and some were newly measured. All data sets were critically compared with the integral thick target yields deduced from the recommended cross sections. In this paper only one reaction for each type of bombarding particles is discussed. A comprehensive paper will be published elsewhere including the results for all the 22 investigated reactions.
\end{abstract}

\section{Introduction}

Charged particle nuclear reactions can be used for monitoring the parameters of bombarding beams. In a coordinated research project (CRP) of the International Atomic Energy Agency (IAEA) several reactions were selected and propose for monitoring purposes. The available experimental data were collected and after critical evaluation recommended cross sections were deduced. The results are available in printed form and also online [1].

In this work a summary of the upgrading process and validation test of the recommended cross section database is presented. Due to the limited length of the paper only one reaction is discussed in more details for each bombarding particle type. In the upgrading process experimental cross sections published earlier, and not yet included in the evaluation work, or data measured after that the original work was closed were collected and added to the initial database in order to improve the quality of the recommended data. In the study 8 proton, 5 deuteron, 3 helium- 3 and 6 alpha particle induced monitor reactions on $\mathrm{Al}, \mathrm{Ti}, \mathrm{Fe}, \mathrm{Ni}$ and $\mathrm{Cu}$ targets were included. The list of reactions is given in table 1 . The original selection criteria were used which are discussed in ref. [1]. In some cases it turned out that new independent data were necessary to be able to make the selection decision in the evaluation process. Therefore additional experiments were performed to measure the excitation function of the reactions in question in order to be able to decide among the available different data sets and to increase the reliability of the final recommended data sets. To validate the selection as well as the recommended cross sections data, experimental thick target yields were collected from the literature while some were newly measured and the gathered data were critically

a Presenting author, e-mail: stakacs@atomki.hu compared with the integral thick target yields deduced from the appropriate recommended cross sections.

\section{Proton induced monitor reactions}

In the study the following reactions were included: ${ }^{27} \mathrm{Al}(\mathrm{p}, \mathrm{x})^{22} \mathrm{Na},{ }^{27} \mathrm{Al}(\mathrm{p}, \mathrm{x})^{24} \mathrm{Na},{ }^{\text {nat }} \mathrm{Ti}(\mathrm{p}, \mathrm{x}){ }^{48} \mathrm{~V}, \quad{ }^{\text {nat }} \mathrm{Ni}(\mathrm{p}, \mathrm{x}){ }^{57} \mathrm{Ni}$, $\left.{ }^{\text {nat }} \mathrm{Cu}(\mathrm{p}, \mathrm{x}){ }^{56} \mathrm{Co}, \quad{ }^{\text {nat }} \mathrm{Cu}(\mathrm{p}, \mathrm{x})\right)^{62} \mathrm{Zn}$, ${ }^{\text {nat }} \mathrm{Cu}(\mathrm{p}, \mathrm{x})^{63} \mathrm{Zn}$, and ${ }^{n a t} \mathrm{Cu}(\mathrm{p}, \mathrm{x})^{65} \mathrm{Zn}$. Additional data for all reactions were found. Data published since the original CRP work was closed in 2001 were collected. The gathered new data sets added to the original database did not change the final result in case of the ${ }^{27} \mathrm{Al}(\mathrm{p}, \mathrm{x})^{24} \mathrm{Na}$, ${ }^{\text {nat }} \mathrm{Ti}(\mathrm{p}, \mathrm{x})^{48} \mathrm{~V}$ and ${ }^{\text {nat }} \mathrm{Cu}(\mathrm{p}, \mathrm{x}){ }^{56} \mathrm{Co}$ reactions, therefore the original fit as recommended curve was kept. In the case of the remaining five reactions the newly added data influenced the selection and initiated new spline fit calculations. The new curves are only slightly different from the original ones, except in one case which is discussed here. It concerns the ${ }^{\text {nat }} \mathrm{Cu}(\mathrm{p}, \mathrm{x})^{62} \mathrm{Zn}$ reaction according to the result of the experiment that was performed for cross checking excitation functions of proton induced reactions used for monitoring purposes on $\mathrm{Ti}$, $\mathrm{Ni}$ and $\mathrm{Cu}$ targets by [2]. The work pointed out that the excitation function for ${ }^{\text {nat }} \mathrm{Cu}(\mathrm{p}, \mathrm{x})^{62} \mathrm{Zn}$ reaction presented in the CRP is too low as the result of an independent evaluation of the reactions in the original work. Two other earlier works [3] [4] also support the new recommended values. The new recommended curve together with the finally selected experimental data and the original fit is presented in figure 1.

The measured thick target yield at $32 \mathrm{MeV}$ is in good agreement with the yield calculated from the new recommended cross section data (see fig. 5). 
Table 1. List of the investigated reactions, number of total/selected experimental data sets, number of newly added datasets, data quality and type of fit for recommended data.

\begin{tabular}{|c|c|c|c|c|}
\hline Reactions & $\begin{array}{c}\text { exp./ } \\
\text { selected. }\end{array}$ & $\begin{array}{l}\text { No. of new } \\
\text { experiments }\end{array}$ & $\begin{array}{c}\text { Data } \\
\text { condition }\end{array}$ & $\begin{array}{c}\text { Recommended } \\
\text { data }\end{array}$ \\
\hline${ }^{27} \mathrm{Al}(\mathrm{p}, \mathrm{x})^{22} \mathrm{Na}$ & $14 / 9$ & 8 & good & New Spline fit \\
\hline${ }^{27} \mathrm{Al}(\mathrm{p}, \mathrm{x})^{24} \mathrm{Na}$ & $16 / 11$ & 7 & scattered & Spline fit \\
\hline${ }^{\text {nat }} \operatorname{Ti}(\mathrm{p}, \mathrm{x})^{48} \mathrm{~V}$ & $16 / 6$ & 6 & good & New Spline fit \\
\hline${ }^{\text {nat }} \mathrm{Ni}(\mathrm{p}, \mathrm{x}){ }^{57} \mathrm{Ni}$ & $21 / 15$ & 2 & good & Spline fit \\
\hline${ }^{\text {nat }} \mathrm{Cu}(\mathrm{p}, \mathrm{x}){ }^{56} \mathrm{Co}$ & $7 / 4$ & 2 & reasonable & Spline fit \\
\hline${ }^{\text {nat }} \mathrm{Cu}(\mathrm{p}, \mathrm{x})^{62} \mathrm{Zn}$ & $12 / 3$ & 7 & reasonable & New Spline fit \\
\hline${ }^{\text {nat }} \mathrm{Cu}(\mathrm{p}, \mathrm{x})^{63} \mathrm{Zn}$ & $24 / 9$ & 3 & good & New Spline fit \\
\hline${ }^{\text {nat }} \mathrm{Cu}(\mathrm{p}, \mathrm{x}){ }^{65} \mathrm{Zn}$ & $30 / 9$ & 5 & good & New Spline fit \\
\hline${ }^{27} \mathrm{Al}(\mathrm{d}, \mathrm{x})^{22} \mathrm{Na}$ & $5 / 3$ & 1 & good & Spline Fit \\
\hline${ }^{27} \mathrm{Al}(\mathrm{d}, \mathrm{x}){ }^{24} \mathrm{Na}$ & $16 / 13$ & 1 & good & New Spline fit \\
\hline${ }^{n a t} \operatorname{Ti}(\mathrm{d}, \mathrm{x})^{48} \mathrm{~V}$ & $5 / 4$ & $1+11$ & good & New Spline fit \\
\hline${ }^{n a t} \mathrm{Fe}(\mathrm{d}, \mathrm{x}){ }^{56} \mathrm{Co}$ & $9 / 7$ & 2 & reasonable & New Spline fit \\
\hline${ }^{\text {nat }} \mathrm{Ni}(\mathrm{d}, \mathrm{x}){ }^{61} \mathrm{Cu}$ & $6 / 4$ & 2 & scattered & New Spline fit \\
\hline$\left.{ }^{27} \mathrm{Al}\left({ }^{3} \mathrm{He}, \mathrm{x}\right)\right)^{22} \mathrm{Na}$ & $7 / 6$ & 1 & scattered & Spline fit \\
\hline${ }^{27} \mathrm{Al}\left({ }^{3} \mathrm{He}, \mathrm{x}\right){ }^{24} \mathrm{Na}$ & $5 / 5$ & 1 & scattered & New Spline fit \\
\hline${ }^{\text {nat }} \mathrm{Ti}\left({ }^{3} \mathrm{He}, \mathrm{x}\right){ }^{48} \mathrm{~V}$ & $4 / 4$ & 1 & scattered & Spline fit \\
\hline$\left.{ }^{27} \mathrm{Al}(\alpha, \mathrm{x})\right)^{22} \mathrm{Na}$ & $13 / 10$ & 1 & scattered & Spline Fit \\
\hline${ }^{27} \mathrm{Al}(\alpha, \mathrm{x}){ }^{24} \mathrm{Na}$ & $16 / 11$ & 0 & scattered & Pade fit \\
\hline${ }^{\text {nat }} \mathrm{Ti}(\alpha, \mathrm{x})^{51} \mathrm{Cr}$ & $11 / 6$ & 1 & reasonable & Pade fit \\
\hline${ }^{\text {nat }} \mathrm{Cu}(\alpha, \mathrm{x}){ }^{66} \mathrm{Ga}$ & $17 / 9$ & $1+2$ & reasonable & New Spline fit \\
\hline${ }^{\text {nat }} \mathrm{Cu}(\alpha, \mathrm{x}){ }^{67} \mathrm{Ga}$ & $14 / 8$ & $1+3$ & reasonable & New Spline fit \\
\hline${ }^{\text {nat }} \mathrm{Cu}(\alpha, \mathrm{x})^{65} \mathrm{Zn}$ & $15 / 8$ & $1+3$ & reasonable & New Spline fit \\
\hline
\end{tabular}

\section{Deuteron induced monitor reactions}

The following reactions were proposed for deuteron beam monitoring: ${ }^{27} \mathrm{Al}(\mathrm{d}, \mathrm{x})^{22} \mathrm{Na},{ }^{27} \mathrm{Al}(\mathrm{d}, \mathrm{x})^{24} \mathrm{Na}$, ${ }^{\text {nat }} \mathrm{Ti}(\mathrm{d}, \mathrm{x})^{48} \mathrm{~V}$, ${ }^{n a t} \mathrm{Fe}(\mathrm{d}, \mathrm{x}){ }^{56} \mathrm{Co}$ and ${ }^{\text {nat }} \mathrm{Ni}(\mathrm{d}, \mathrm{x}){ }^{61} \mathrm{Cu}$. The different available data sets in the original database for the ${ }^{27} \mathrm{Al}(\mathrm{d}, \mathrm{x})^{22} \mathrm{Na}$ and ${ }^{27} \mathrm{Al}(\mathrm{d}, \mathrm{x})^{24} \mathrm{Na}$ reactions are in good agreement with each other, while for the other three reactions the data were somewhat more scattered. In case of the ${ }^{\text {nat }} \mathrm{Ti}(\mathrm{d}, \mathrm{x})^{48} \mathrm{~V}$ reaction no recommended data were given below $10 \mathrm{MeV}$ due to unreliable data in that low energy region. Since the CRP was closed new data were published for each investigated reaction. Generally the newly added data confirmed the earlier results and the newly calculated recommended cross section curves have no significant difference from the original ones. To resolve the problem in the low energy region of the ${ }^{\text {nat }} \mathrm{Ti}(\mathrm{d}, \mathrm{x})^{48} \mathrm{~V}$ reaction a new measurement was performed. In that experiment detailed cross sections were determined below $10 \mathrm{MeV}$ [5]. Using this new data and considering only shape information of the low energy part of the excitation function measured in several other independent experiments, new recommended cross sections were calculated from threshold up to $50 \mathrm{MeV}$. The newly added data modified the evaluation process which resulted in a new group of consistent selected data sets and consequently a new recommended cross section curve. The new curve is different in shape from the earlier one around the maximum and is extended down to the threshold energy, see figure 2 . For the ${ }^{27} \mathrm{Al}(\mathrm{d}, \mathrm{x})^{22} \mathrm{Na}$ reaction the original recommended cross section curve was kept, while for the remaining 3 reactions new spline fits were calculated which are very close to the ones given in the original CRP.

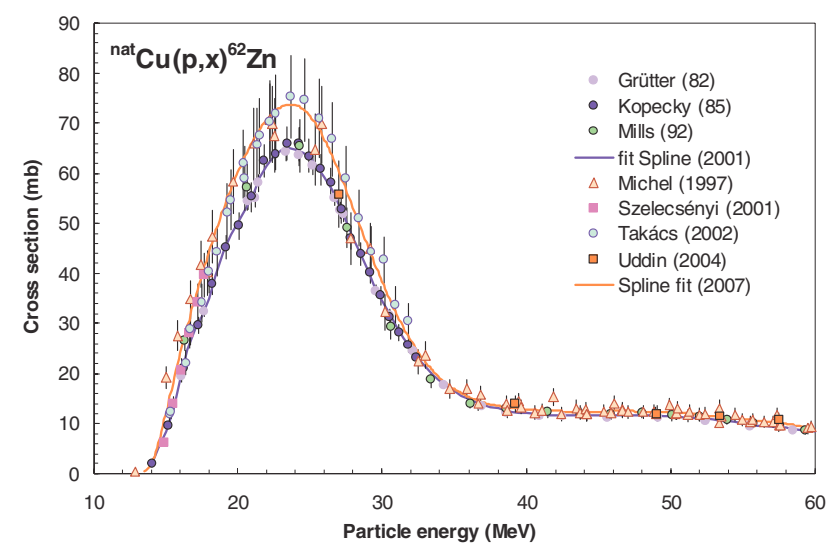

Fig. 1. New recommended cross sections for the ${ }^{\text {nat }} \mathrm{Cu}(\mathrm{p}, \mathrm{x})^{62} \mathrm{Zn}$ reaction.

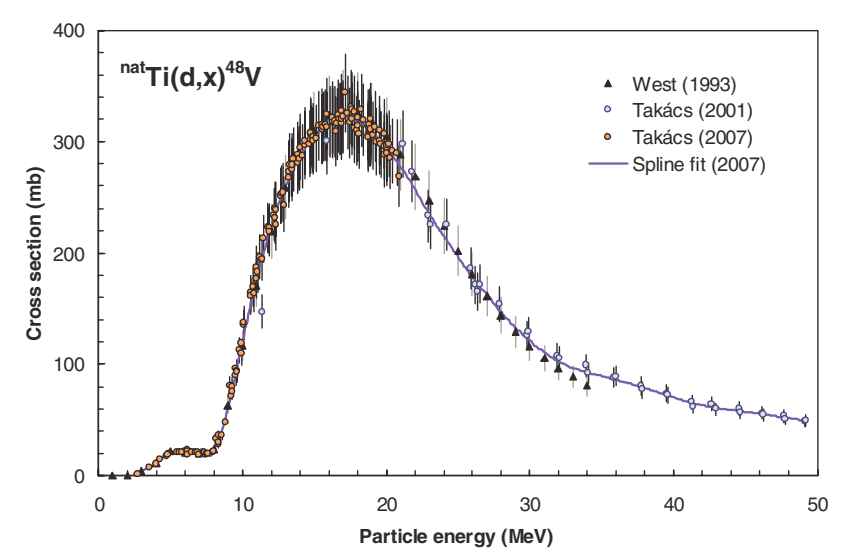

Fig. 2. New recommended excitation function for the ${ }^{\text {nat }} \mathrm{Ti}(\mathrm{d}, \mathrm{x})^{48} \mathrm{~V}$ reaction from threshold up to $50 \mathrm{MeV}$.

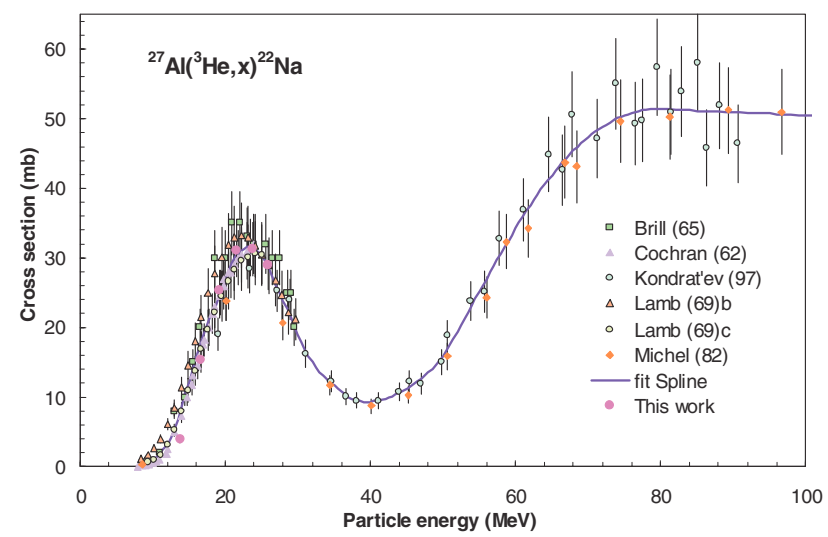

Fig. 3. Only one new data set was included in the database that does not influence the selection, therefore the original recommended cross sections were kept for the ${ }^{27} \mathrm{Al}\left({ }^{3} \mathrm{He}, \mathrm{x}\right)^{22} \mathrm{Na}$ reaction.

The calculated integral thick target yield is in good agreement with the one measured at $22 \mathrm{MeV}$ (see fig. 5). 


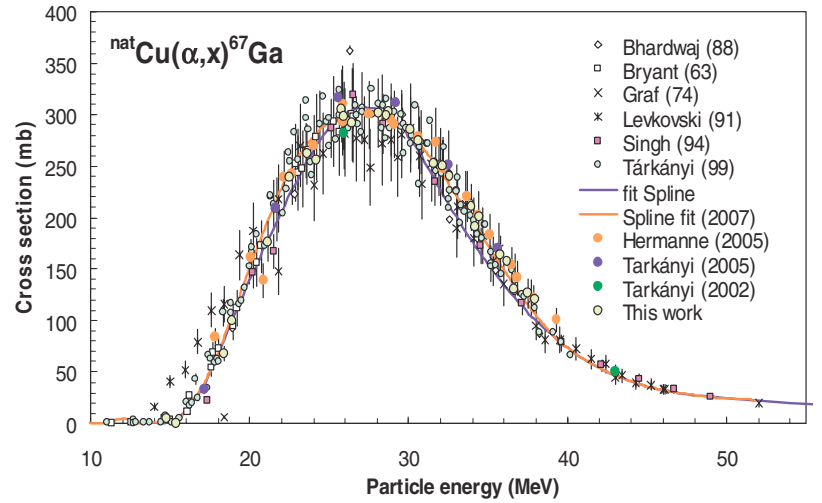

Fig. 4. New recommended excitation function for the ${ }^{\text {nat }} \mathrm{Cu}(\alpha, \mathrm{x})^{67} \mathrm{Ga}$ reaction. As the new data indicate the cross section curve is wider.

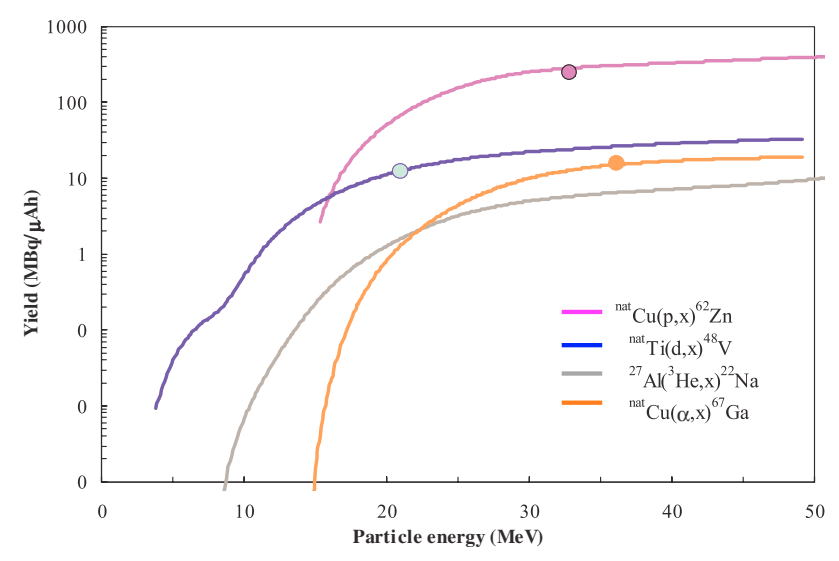

Fig. 5. Thick target yields calculated from recommended cross sections and experimental thick target yield data measured separately are in good agreement. No experimental data was found for the ${ }^{27} \mathrm{Al}\left({ }^{3} \mathrm{He}, \mathrm{x}\right){ }^{22} \mathrm{Na}$ reaction.

\section{Helium-3 induced monitor reactions}

The following three reactions were proposed in the CRP for monitoring the parameters of helium-3 particle beams: ${ }^{27} \mathrm{Al}\left({ }^{3} \mathrm{He}, \mathrm{x}\right){ }^{22} \mathrm{Na},{ }^{27} \mathrm{Al}\left({ }^{3} \mathrm{He}, \mathrm{x}\right){ }^{24} \mathrm{Na}$ and ${ }^{\mathrm{nat}} \mathrm{Ti}\left({ }^{3} \mathrm{He}, \mathrm{x}\right){ }^{48} \mathrm{~V}$. Relatively few data are available for these reactions and the data are rather scattered, therefore new measurements would be necessary to provide more reliable data for each reactions. To help the selection among the available data sets we have performed new experiment on $\mathrm{Al}$ and $\mathrm{Ti}$ targets stacked together and irradiated at $28 \mathrm{MeV}$. The results of this independent experiment confirmed the recommended data given in the CRP earlier, therefore no new recommended data were calculated. In general the quality of the available data sets for these three investigated reactions needs further improvements in order to be able to give more reliable recommended data for these monitor reactions.

This is specially the case in the high energy region where only two data sets for aluminum targets and only one data set for titanium targets exist. The newly added data did not modify the selection among the available data, and hence the original fits were kept as recommended data, except in the case of ${ }^{27} \mathrm{Al}\left({ }^{3} \mathrm{He}, \mathrm{x}\right){ }^{24} \mathrm{Na}$ where the original Padé fit was replaced by a new spline fit which is in better agreement with the selected experimental data.

\section{Alpha particle induced monitor reactions}

The following six reactions were proposed for monitoring alpha particle beams: ${ }^{27} \mathrm{Al}(\alpha, \mathrm{x}){ }^{22} \mathrm{Na}, \quad{ }^{27} \mathrm{Al}(\alpha, \mathrm{x})^{24} \mathrm{Na}$, ${ }^{\text {nat }} \mathrm{Ti}(\alpha, \mathrm{x}){ }^{51} \mathrm{Cr}, \quad{ }^{\text {nat }} \mathrm{Cu}(\alpha, \mathrm{x}){ }^{66} \mathrm{Ga}$, ${ }^{\text {nat }} \mathrm{Cu}(\alpha, \mathrm{x}){ }^{67} \mathrm{Ga}$ and ${ }^{\text {nat }} \mathrm{Cu}(\alpha, \mathrm{x})^{65} \mathrm{Zn}$. New experiments were performed on $\mathrm{Ti}$ and $\mathrm{Cu}$ targets stacked together and the ${ }^{\text {nat }} \mathrm{Ti}(\alpha, \mathrm{x})^{51} \mathrm{Cr}$, ${ }^{\text {nat }} \mathrm{Cu}(\alpha, \mathrm{x}){ }^{66} \mathrm{Ga},{ }^{\text {nat }} \mathrm{Cu}(\alpha, \mathrm{x}){ }^{67} \mathrm{Ga}$ and ${ }^{\text {nat }} \mathrm{Cu}(\alpha, \mathrm{x}){ }^{65} \mathrm{Zn}$ reactions were cross checked. Additional data were found which were measured on copper and used as monitor reactions in other independents experiments [6-8], therefore only the shape information of the excitation functions was used in the evaluation process. In the light of these new results the recommended cross sections for ${ }^{\text {nat }} \mathrm{Ti}(\alpha, \mathrm{x})^{51} \mathrm{Cr}$, ${ }^{\text {nat }} \mathrm{Cu}(\alpha, \mathrm{x}){ }^{66} \mathrm{Ga}$ and ${ }^{\text {nat }} \mathrm{Cu}(\alpha, \mathrm{x}){ }^{65} \mathrm{Zn}$ reactions were confirmed while in the case of the ${ }^{\text {nat }} \mathrm{Cu}(\alpha, \mathrm{x}){ }^{67} \mathrm{Ga}$ reaction a new spline fit was calculated and given as new recommended cross sections. The new curve has a wider shape, otherwise the amplitude of the excitation function remained the same. The newly added data and the newly calculated recommended cross section curve are reproduced in figure 4. together with the original ones and the final selected data sets for the ${ }^{\text {nat }} \mathrm{Cu}(\alpha, \mathrm{x}){ }^{67} \mathrm{Ga}$ reaction.

In the case of aluminum targets the available data require further improvement. For the reaction ${ }^{27} \mathrm{Al}(\alpha, \mathrm{x})^{22} \mathrm{Na}$ only one additional data set was found which needed to be normalized since the published data were two orders of magnitude higher than the others. The available data for this reaction are scattered. In the case of ${ }^{27} \mathrm{Al}(\alpha, \mathrm{x})^{24} \mathrm{Na}$ reaction no additional data was found. On the other hand the available data sets are more consistent than for the ${ }^{27} \mathrm{Al}(\alpha, \mathrm{x})^{22} \mathrm{Na}$ reaction.

\section{Validation of the monitor reactions}

To validate the recommended cross sections thick target yields were calculated from the recommended cross sections for each reaction and were compared with experimental thick target yields collected from literature. Also in this work thick Al, $\mathrm{Ti}, \mathrm{Fe}, \mathrm{Ni}$ and $\mathrm{Cu}$ targets were irradiated with proton, deuteron and alpha particle beams and we measured the produced activity. The measured production yields were corrected to have physical yields for each investigated reaction and compared with those calculated from the recommended cross sections. Figure 5 shows the results for the ${ }^{\text {nat }} \mathrm{Cu}(\mathrm{p}, \mathrm{x})^{62} \mathrm{Zn}$, ${ }^{\text {nat }} \mathrm{Ti}(\mathrm{d}, \mathrm{x})^{48} \mathrm{~V}$ and ${ }^{n a t} \mathrm{Cu}(\alpha, \mathrm{x}){ }^{67} \mathrm{Ga}$ reactions. In the case of ${ }^{3} \mathrm{He}$ particles induced reactions no integral data were found in the literature, therefore only the calculated thick target yield is shown in the figure. The experimental values are in good agreement with the calculated ones indicating the quality of the recommended cross section. 


\section{Summary}

In the study 8 proton, 5 deuteron, 3 helium-3 and 6 alpha induced monitor reactions on $\mathrm{Al}, \mathrm{Ti}, \mathrm{Fe}, \mathrm{Ni}$ and $\mathrm{Cu}$ targets were included. The data are available at the URL http://wwwnds.iaea.or.at/medical/.

In a throughout literature survey additional data were searched. In some cases additional experiments were performed to measure new data to help the decision among the available data sets. The gathered new data were analyzed critically and added to the selected data sets. Using the selected group of data a cubic spline statistical fitting method was used to produce recommended cross section curves. Table 1 collects some information about the upgrading process. It gives the number of available datasets and the selected ones in column 2. Column 3 shows the number of newly added data sets. The general quality of the selected data is indicated in column 4, while in the last column "New Spline fit" means that a new calculation was done for presenting the recommended data.

In the upgrade process new figures and tables with upgraded data were created for each reaction and integral thick target yields were calculated from the recommended cross sections and added to the database (omitted in the original work). The final upgraded version will be published soon on the same URL.

The upgraded values, recommended cross sections and yields, will be also compiled in EXFOR format for each reaction, and will be included in the EXFOR database.

\section{References}

1. Charged particle cross section database for medical radioisotope production: diagnostic radioisotopes and monitor reactions, Vienna, IAEA. IAEA-TECDOC-1211, 2001, http://www-nds. iaea.or.at/medical/.

2. S. Takács, F. Tárkányi, M. Sonck, A. Hermanne, Nucl. Instrum. Meth. Phys. Res. B 188, 106 (2002).

3. R. Michel, R. Bodemann, H. Busemann, R. Daunke, M. Gloris, H.J. Lange, B. Klug, A. krins, I. Leya, M. Luepke, S. Neumann, H. Reinhardt, M. Schnatz-Buettgen, U. Herpers, Th. Schiekel, F. Sudbrock, B. Holmqvist, H. Conde, P. Malmborg, M. Suter, B. Dittrich-Hannen, P.W. Kubik, H.A. Sinald, D. Filges, Nucl. Instrum. Meth. Phys. Res. B 129, 153 (1997).

4. F. Szelecsényi, F. Tárkányi, S. Takács, A. Hermanne, M. Sonck, Yu. Shubin, M.G. Mustafa, Z. YouXiang, Nucl. Instrum. Meth. Phys. Res. B 174, 47 (2001).

5. S. Takácș, B. Király, F. Tárkányi, A. Hermanne (to be published).

6. A. Hermanne, F. Tárkányi, S. Takács, Z. Szûcs, Yu.N. Shubin, A.I. Dityuk, Appl. Radiat. Isot. 63, 1 (2005).

7. F. Tárkányi, S. Takács, F. Ditrói, Gy. Csikai, A. Hermanne, M.S. Uddin, M. Haiwara, M. Baba, Yu.N. Shubin, A.I. Dityuk, in Proceedings of International Conference on Nuclear Data for Science and Technology, Santa Fe, NM, USA, 2004, edited by R.C. Haight, P. Talou, T. Kawano, et al., AIP Conference Proceedings 769, 1015 (2005).

8. F. Tárkányi, F. Ditrói, F. Szelecsényi, M. Sonck, A. Hermanne, Nucl. Instrum. Meth. Phys. Res. B 198, 11 (2002). 